\title{
Description of a New Species of Pseudorabdion (Serpentes: Colubridae) from Panay Island, Philippines with a Revised Key to the Genus
}

\author{
RAFE M. BROWN ${ }^{1,2}$, Alan E. LEVITON ${ }^{3}$, AND Rogelio V. Sison ${ }^{4}$
}

\begin{abstract}
${ }^{I}$ Section of Integrative Biology and Texas Memorial Museum, University of Texas, Austin, Texas, 78712 (rafe@mail.utexas.edu); ${ }^{2}$ Geier Collections and Research Center, Museum of Natural History and Science, Cincinnati Museum Center, 1720 Gilbert Avenue, Cincinnati, OH 45202-1401; ${ }^{3}$ Department of Herpetology, California Academy of Sciences, San Francisco, CA 94118 (leviton@sfsu.edu); 4 Zoology Department, National Museum of the Philippines, Executive House, P. Burgos Street, Manila, Philippines (nmuseum@webquest.com).
\end{abstract}

Abstract.- We describe a new species of snake in the colubrid genus Pseudorabdion from the western coastal mountain range of Panay island, Philippines. The new species appears to be related to the members of the $P$. mcnamarae species group ( $P$. mcnamarae and $P$. taylori from the Philippines, $\mathrm{P}$. albonuchalis, and $P$. saravacensis from Borneo, and $P$. sarasinorum from Sulawesi) but differs from each of these species by characters of scalation and color pattern. The new species is one of several other recently-discovered vertebrates from Panay island. Together, these discoveries suggest that diversity and endemism patterns of the Negros-Panay Pleistocene aggregate island platform (Negros, Panay, Cebu and Masbate islands) are more complex and interesting than previously thought.

\section{Introduction}

While engaged in a biological reconnaissance survey ${ }^{5}$ of the western coastal mountain range of Panay Island (Fig. 1), the senior author collected two specimens of what appeared at the time to be Pseudorabdion mcnamarae, a species already well know from Negros Island. On closer examination it was discovered that the Panay specimens differed in significant details from the Negros population while sharing features with $P$. taylori, known from Mindanao, and with $P$. albonuchalis, a species earlier known only from the type specimen (but see Inger and Leviton, 1966), which can no longer be located, and said to have come from Sarawak, Borneo. The observed differences among these related species leads us to believe that the Panay specimens represent a previously unrecognized, taxonomically distinct population of Pseudorabdion allied to the section of the genus Pseudorabdion whose members possess an elongate loreal (lori-ocular) that borders the orbit anteriorly.

\section{Pseudorabdion talonuran new spe- cies (Figs. 2-3)}

Holotype: PNM 2712 (Field no. PNM/CMNH 671), adult male, collected on western foothills of Mt. Madja-as ( $11^{\circ} 23^{\prime} \mathrm{N}, 122^{\circ} 09^{\prime} \mathrm{E}$; elev. $\left.1500 \mathrm{~m}\right)$, Barangay Allojipan, Municipality of Culasi, Antique Province, Panay Island, Philippines, 28 May 1992 by Rafe Brown and Roger Sison.
Paratype: CMNH 5076 (Field no. PNM/CMNH 670 ), young male, other data as for holotype except it was collected at $1410 \mathrm{~m}$.

Etymology: The specific epithet is chosen from the Antique Province dialect Caray-a, and is derived from the words, "talon" (forest) and "uran" (rain), in reference to the high elevation rain forest habitat where the new species was collected on Mt. Madja-as.

Diagnosis: Elongate loreal (=lori-ocular) present, extending from the posterior border of the nasal to the orbit of the eye; ventrals (M) 139-146; subcaudals (M) 36-39; total of ventrals plus subcaudals (M) 175185; scales of dorsum each edged with a mottling of brown pigment, the posterior and central portions of each scale pale, lacking a dense infusion of dark pigment, the lateral and latero-ventral scales with larger pale areas than those on the dorsum; no distinct nuchal collar but pattern of pale centers and dark rims characterizes nuchal scales and head shields, which are somewhat mottled dark and light.

Pseudorabdion talonuran belongs to the section of the genus Pseudorabdion characterized by the presence of a loreal (lori- ocular) shield. From the allied Philippine $P$. mcnamarae, it differs in lacking a pale nuchal color in adults and in having more than 30 subcaudals in both males and females; from P. taylori it differs in having the centers and apical tips of the dorsal scales nearly pigmentless whereas in $P$. taylori the centers are pale brown, and in having the hemipenes minutely 
spinose (in $P$. taylori the apical tips are calyculate). Among the non-Philippine species having a lori-ocular, $P$. talonuran differs from $P$. sarasinorum in having the anterior chin shields in contact with the mental, from $P$. albonuchalis in having fewer subcaudals (3639 vs. 43) and the frontal not border the eye, and from $P$. saravacensis in having a greater number of subcaudals (36-39 vs. fewer than 30) and fewer maxillary teeth ( 8 vs. 14). From the remaining species in the genus, it differs in having an elongate loreal (lori-ocular) shield that borders the eye.

Description of holotype: (Adult male) Rostral as high as wide, portion visible from above slightly greater than length of internasal suture; internasals small, greatest length about one-half greatest length of prefrontals, in contact with rostral, nasal, loreal and prefrontal; common suture between prefrontals about four-fifths length of frontal; prefrontal bordering eye between loreal and supraocular, also in contact with internasals; left prefrontal in contact with both internasals (because internasal suture offset from midline); frontal two-thirds length of parietals, subtriangular, three-fourths as wide as long, in contact with prefrontals, supraocular and parietals, but not bordering eye; supraocular distinct, not fused to ocular brill; maximum length of parietals slightly greater than distance to tip of snout; nasal quadrangular, undivided, resting on first and in contact with second supralabials, nostril pierced in anterior lower quadrant; loreal elongate, resting on second and third supralabials, about twice as long as its distance to tip of snout, bordering eye; preocular absent (or more likely fused to form an elongate loreal [lori-ocular]); postocular, subquadrangular, about one half size of supraocular, in contact with fourth and fifth supralabials, not as high as eye, its lower border extending below level of eye and inserting between two supralabials; eye small, its diameter equal to its distance from mouth, pupil round; five supralabials and one large postsupralabial, supralabials three and four border eye, fifth largest and broadly in contact with parietals, followed by third, second, fourth, and first in descending order of

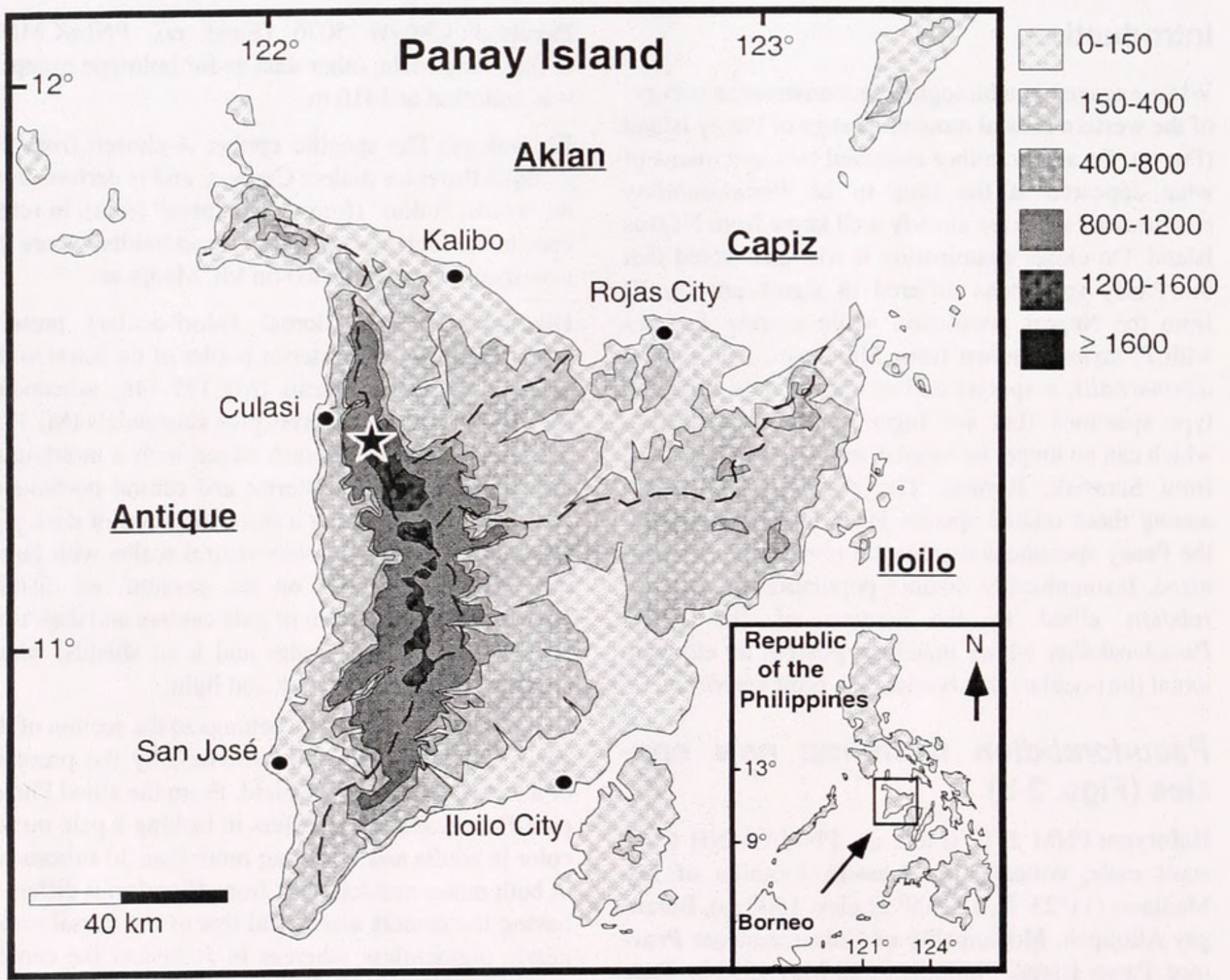

Fig. 1. Map of Panay Island, showing its position in the Philippines (inset), major cities (darkened circles), provinces (dashed lines; names underlined) and elevational topography (see key). The type locality (Mt. Madja-as) of Pseudorabdion talonuran is indicated with a star. 

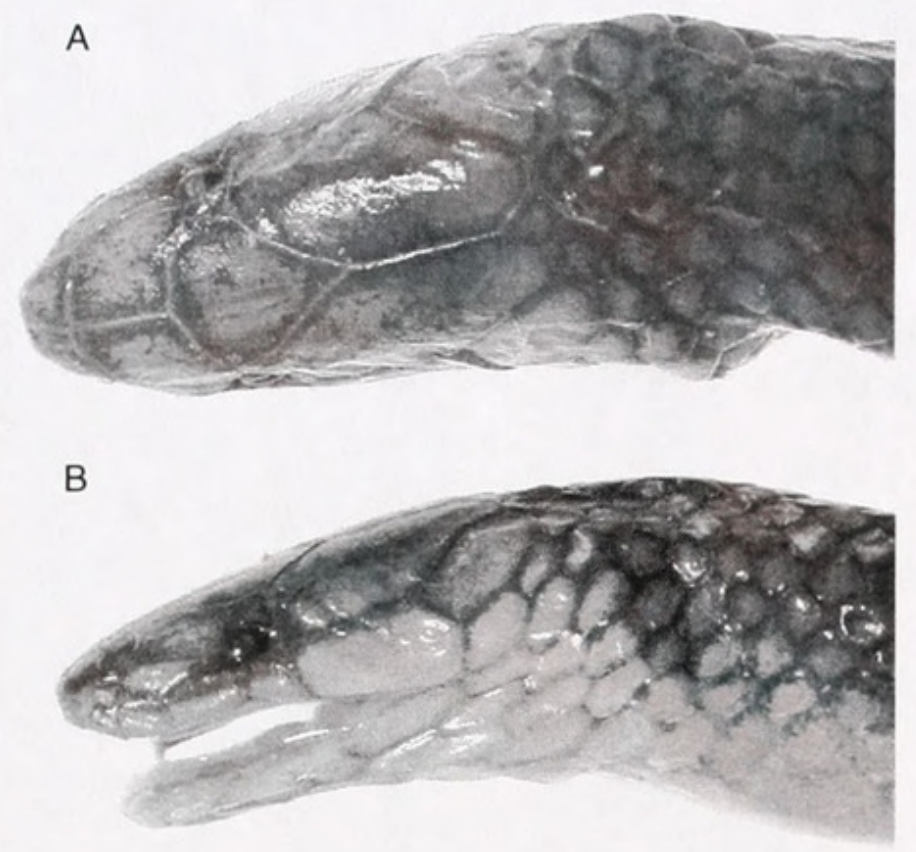

Fig. 2.Dorsal (A) and lateral (B) views of head of holotype of Pseudorabdion talonuran.

size; one large "posterior temporal" between postlabial and parietal; mental in contact with elongate anterior chin shields; infralabials five, first three in contact with anterior chin shields, third and fourth bordering posterior chin shields; posterior chin shields about three-fourths length of anterior pair, separated from one another in the midline for two-thirds their length by insertion of a gular scale, and about same size as bordering gular scales; maxillary teeth eight.

Scales smooth, without apical pits, in 15 longitudinal rows, not reducing posteriorly before vent; ventrals $146 \mathrm{~mm}$; subcaudals $39 \mathrm{~mm}$, paired; anal undivided.

Hemipenes extend in situ to 8th subcaudal plate, forked at the level of the 6th plate; apical ends with minute spines.

Total length $265 \mathrm{~mm}$; tail $46 \mathrm{~mm}$; head length (tip of snout to angle of jaws) $11.25 \mathrm{~mm}$, (tip of snout to posterior edge of parietals) $9.1 \mathrm{~mm}$; diameter of eye $0.8 \mathrm{~mm}$.

Color pattern (in alcohol): Dorsal scales each with irregular dark borders; apical end and centers pale, nearly pigmentless, pigmentless areas larger and more distinct laterally; ventrals unpigmented except for lateral edges; no nuchal collar.

Paratype: The paratype, a young male, differs from the holotype in the following particulars: ventrals 139 ; subcaudals 36 ; snout-vent length, $265 \mathrm{~mm}$; tail length $47 \mathrm{~mm}$; apical ends of hemipenes do not appear to be spinose (but the everted organ is poorly preserved and difficult to examine).

Ecological notes: The forest habitat of the new species on Mt. Madja-as (Fig. 4) has been classified by Whitmore (1984) as the transition zone between mixed dipterocarp (submontane) and mossy (upper montane) forests. The forest consists of two strata, a canopy of $10 \mathrm{~m}$ and subcanopy of 3-4 $\mathrm{m}$ with emergent trees as high as $18 \mathrm{~m}$; an herb and shrub layer vegetation was also present. The forest near the collection site was mossy and contained high densities of epiphytic ferns and orchids. The topography was qualitatively characterized as steep, with numerous sheer rocky valleys and forest-covered ridges (see Ferner, et al., 1997 for more details.) Both holotype and paratype were found beneath logs.

Remarks: The section of the genus Pseudorabdion characterized by the presence of an elongate loreal (lori-ocular) that borders the orbit, termed here the "mcnamarae" section, includes three species in the Philippines, P. mcnamarae, P. taylori, and P. talonuran, and three non-Philippine species, $P$. albonuchalis and $P$. saravacensis from Sarawak, and P. sarasinorum from Gunung (Volcano) Soudara, Sulawesi.

Five species ( $P$. longiceps, $P$. ater, P. oxycephalum, $P$. eiselti, and $P$. montanum) lack the loreal (lori-ocular); the prefrontals are in contact with the second and third upper labials. Of the forms lacking a distinct

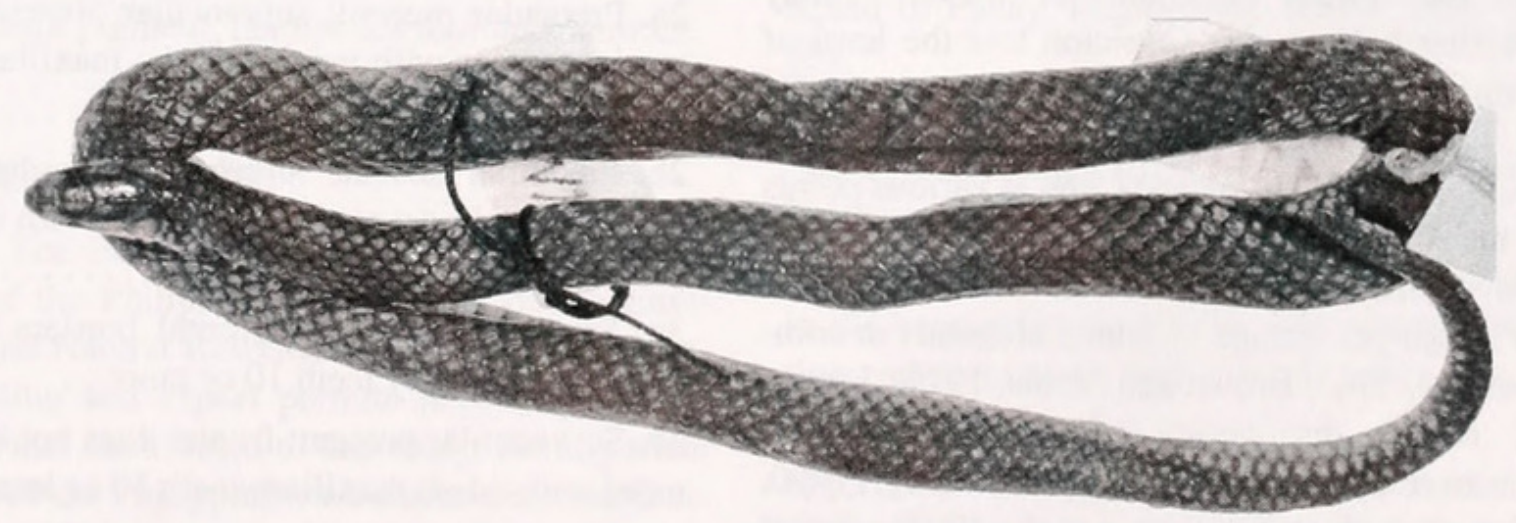

Fig. 3.Dorsal view of holotype (PNM 2712) of Pseudorabdion talonuran. 


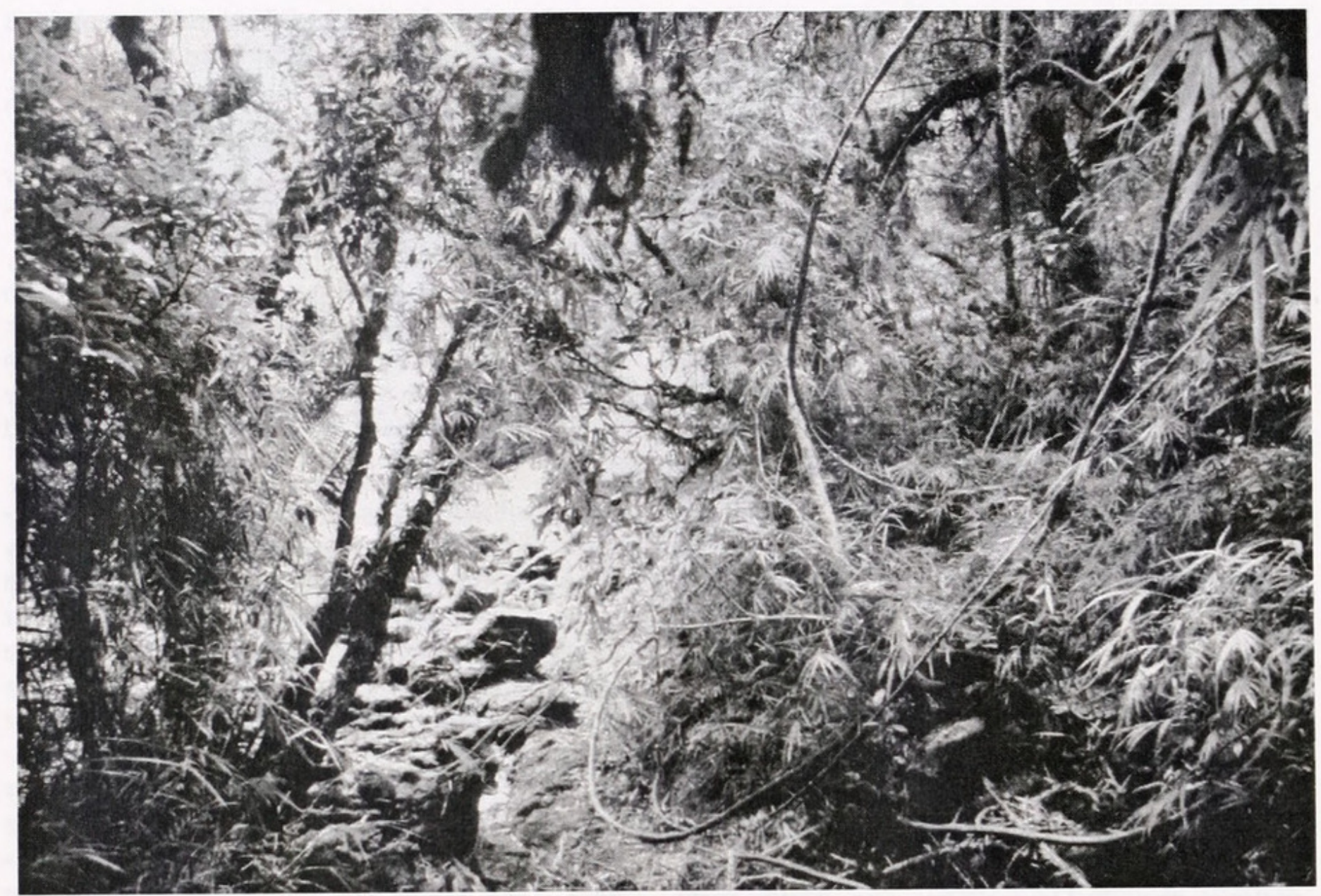

Fig. 4.Cloud forest habitat of Pseudorabdion talonuran at the type locality: Mt. Madja-as, Antique Province, Panay Island, Philippines.

loreal (or if a small scale is present in the loreal position, a rare occurrence among this group, it is neither elongate nor does it border the orbit), $P$. oxycephalum, $P$. ater, and $P$. montanum are confined to the Philippines, $P$. eiselti is known only from the type locality at Padang, Sumatra, and $P$. longipes has been collected at many localities on the islands of Borneo, Sulawesi, Nias, and Sumatra, from Singapore and elsewhere north along the Malay Peninsula, from the Riau (Riou) Archipelago, and as far north as Ban Gnara and Patani, in southern Thailand.

The presence of this new, endemic species of snake in the coastal mountains of western Panay island further bolsters our suspicion that the level of endemism on Panay is greater than previously thought. By virtue of the fact that Panay was intermittently connected to Negros and Cebu at various points during the Pleistocene (Heaney, 1986), biogeographers have justifiably expected that these islands to possess a high percentage of faunal elements in common (Leviton, 1963; Brown and Alcala, 1970). Nevertheless, recent discoveries of other vertebrates endemic to Panay (Gonzales and Kennedy, 1990, 1996; Brown et al., 1997; Ferner et al., 1997) suggest that its high elevation montane regions warrant more intensive biodiversity survey efforts in the near future.

\section{Key to the Species of Pseudorabdion}

\section{(Modified from Inger and Leviton, 1966)}

1a. Lori-ocular (loreal) shield absent (if present, does not border orbit); prefrontal in contact with upper labials

1b. Lori-ocular shield present, very distinct, elongate, borders orbit; prefrontal not in contact with upper labials

.7

2a. Preocular present; supraocular present; internasal not in contact with upper labials; maxillary teeth 1112 . .

P. longipes

2b. Preocular absent; supraocular present or absent; internasals almost always in contact with upper labial

3a. Supraocular absent; frontal borders orbit; nasal divided; maxillary teeth 10 or more ......... 4

3b. Supraocular present; frontal does not border orbit; nasal undivided; maxillary teeth 10 or less ..... 5 4a. Postocular absent; maxillary teeth $10 \ldots$. P. ater 
4b. Postocular present; maxillary teeth $22-25 \ldots \ldots$. P. collaris

5a. Postocular not fused to supraocular; ventrals 130; subcaudals $12 \ldots \ldots \ldots \ldots \ldots \ldots \ldots$. eiselti 5b. Postocular and supraocular fused; ventrals greater than 140 ; subcaudals greater than $15 \ldots \ldots \ldots 6$ 6 a. Each scale of outer row with dark centers and pale borders; ventrals uniformly dark brown except for extreme posterior outer edges which are pale; ocular shield usually fused to combined supra- and postoculars; subcaudals (M) 22-24, (F) 16- 17 . . . . . . . .

\section{P. oxycephalum}

6 b. Each scale of outer row with pale centers; ventrals whitish with dark brown more or less confined to a broad median band; ocular shield not fused to combined supra- and postoculars; subcaudals (M) 28; (F) 21-24.................... montanum

7a. Anterior chin shields not in contact with mental; nasal shield divided ........... P. sarasinorum

7b. Anterior chin shields in contact with mental; nasal shield not divided $\ldots \ldots \ldots \ldots \ldots \ldots \ldots \ldots$

8a. Maxillary teeth greater than $15 \ldots \ldots \ldots \ldots 9$

8 b. Maxillary teeth fewer than $10 \ldots \ldots \ldots \ldots$

9a. Ventrals greater than 125 ; subcaudals greater than $40 \ldots \ldots \ldots \ldots \ldots \ldots$. . . albonuchalis

9b. Ventrals fewer than 120 ; subcaudals fewer than 30 P. saravacensis

10a. Pale nuchal collar usually present; subcaudals 17-30; distal portion of hemipenes minutely spinose P. mcnamarae

10b. Pale nuchal collar absent in adults; subcaudals greater than $30 \ldots \ldots \ldots \ldots \ldots \ldots \ldots \ldots \ldots$

11a. Dorsal scales uniform pale brown, each scale thinly edged with pigmentless border; distal portion of hemipenes calyculate ........... P.taylori

11b. Dorsal scales with pale, nearly pigmentless centers and apical tips, anterior borders of each scale with brown mottling, larger areas of latero-ventral scales devoid of dark pigment; hemipenes minutely spinose

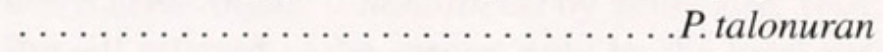

\section{Acknowledgments}

We thank The Protected Areas and Wildlife Bureau (PAWB) of the Philippines Department of the Environment and Natural Resources (DENR) for facilitating collecting and export permits necessary for the field work that contributed to this study. For logistical assistance in the Philippines, we thank Corazon Catibog-Sinha (DENR), A. Alcala (Silliman University),
P. Gonzales (PNM), R. Kennedy (CMNH) and the provincial DENR authorities of Antique Province.

For the loans of specimens, we thank the following individuals and their respective institutions (museum acronyms, with the exception of CMNH, follow Leviton et al., 1985): J. Vindum and R. Drewes (CAS), R. Kennedy and J. Ferner (CMNH), and P. Gonzales (PNM). Financial support for RMB's travel to CAS was provided by the C. Stearns Fellowship of the California Academy of Sciences. We thank J. Barcelona (PNM) for assistance with the Caray-a derivation of the new species name.

Support for RMB's field work was provided by the Society for the Study of Amphibians and Reptiles, the Roschman Student Enrichment fund of the College of Arts and Sciences, and the Zoology and Botany Departments of Miami University (Oxford, Ohio). The PNM/CMNH PBI was supported by a grant (to R. Kennedy and P. Gonzales) from the John D and Catherine T. MacArthur Foundation and by the benefactors of Cincinnati Museum of Natural History.

We thank D. Cannatella and A. Diesmos for comments on earlier drafts of this manuscript.

\section{Literature Cited}

Brown, W. C. and A. C. Alcala. 1970. The zoogeography of the Philippine Islands, a fringing archipelago. Proc. California Acad. Sci. 38:105-130.

Brown, W. C., R. M. Brown, and A. C. Alcala. 1997. Species of the hazelae group of Platymantis (Amphibia: Ranidae) from the Philippines, with descriptions of two new species. Proc. California Acad. Sci. 49:405-421, Figs. 1-4.

Ferner, J. W., R. M. Brown, and A. E. Greer. 1997. A new genus and species of moist closed canopy forest skinks from the Philippines. Jour. Herpetol. 31:187192, Figs. 1-3.

Gonzales, P.C. and R.S. Kennedy. 1990. A new species of Stachyris babbler (Aves: Timaliidae). from the island of Panay, Philippines. Wilson Bull. 102: $367-$ 379 .

Gonzales, P.C. and R.S. Kennedy. 1996. A new species of Crateromys (Rodentia: Muridae) from Panay, Philippines. J. Mamm. 77:25-40.

Heaney, L. R. 1986. Biogeography of small mammals in SE Asia: estimates of rates of colonization, extinction and speciation. Biol. Jour. Linnaen Soc., London 28:127-165, Figs. 1-8.

Inger, R. F., and A. E. Leviton. 1961. A new colubrid snake of the genus Pseudorabdion from Sumatra. Fieldiana: Zoology 44:45-47, Fig. 1. 
Inger, R. F., and A. E. Leviton. 1966. The taxonomic status of Bornean snakes of the genus Pseudorabdion Jan and of the nominal genus Idiopholis Mocquard. Proc. California Acad. Sci., 34:307-314, Figs. 1-3.

Leviton, A. E., and W. C. Brown. 1959. A review of the genus Pseudorabdion with remarks on the status of the genera Agrophis and Typhlogeophis (Serpentes: Colubridae). Proc. California Acad. Sci., 29:475-508, Figs. 1-10.

Leviton, A. E. 1963. Remarks on the zoogeography of Philippine terrestrial snakes. Proc. California Acad. Sci. 31:369-416, Fig. 1.

Leviton, A. E., R. H. Gibbs, Jr., E. Heal, and C. E. Dawson. 1985. Standards in herpetology and ichthyology: Part I. Standard symbolic code for institutional resource collections in herpetology and ichthyology. Copeia 1985: 802-832.

\section{Appendix 1. Specimens Examined}

In addition to specimens listed in earlier publications by Leviton and Brown (1959) and by Inger and Leviton (1961 and 1966), the following new materials have been examined:
Pseudorabdion mcnamarae: Philippine Islands: Negros Island: Negros Occidental Prov.: CAS 185577 - Panakiyo, 22 km E Isabela, 16 April 1960 by Q. and L. Alcala. Negros Oriental Prov.: CAS 186052 - Cuernos de Negros, 3600-3800 ft., 24 December 1959 by Q. Alcala and R. Empeso.

P. talonuran: See Holotype and Paratype sections for this species.

P. albonuchalis: Malaysia: Sarawak (Fourth Division): CAS 101500 - Niah, Tangap, 6 December 1960 by T. Harrison.

P. oxycephalum Philippine Islands: Panay Island: Aklan Prov.: CAS 137643 - Nabas, Laserna Barrio, 12 May 1973 by L. Alcala. Negros Island: Negros Occidental Prov.: CAS 185453-185457 - Hinoba-an Town, barrios Alim and Asia, 9-10 June 1967 by L. Alcala and party; Barrio Asia, 30 May-3 June 1967 by A. Alcala, L. Pelingon and F. Pelingon. Negros Oriental Prov.: CAS 110974 - Camp Lookout, Valencia, 14 June 1967 by L. and F. Pelingon; 24-25 km NW of Bondo [about $10 \mathrm{~km} \mathrm{~N}$ of Siaton], 27-31 December 1958 by A. Alcala and party. 


\section{$2 \mathrm{BHL}$ Biodiversity Heritage Library}

Brown, Rafe M., Leviton, A E, and Sison, R V. 1999. "Description of a new species of Pseudorabdion (Serpentes: Colubridae) from Panay Island, Philippines with a revised key to the genus." Asiatic herpetological research 8, 7-12. https://doi.org/10.5962/bhl.part.24610.

View This Item Online: https://www.biodiversitylibrary.org/item/21157

DOI: https://doi.org/10.5962/bhl.part.24610

Permalink: https://www.biodiversitylibrary.org/partpdf/24610

\section{Holding Institution}

Harvard University, Museum of Comparative Zoology, Ernst Mayr Library

\section{Sponsored by}

Harvard University, Museum of Comparative Zoology, Ernst Mayr Library

\section{Copyright \& Reuse}

Copyright Status: In copyright. Digitized with the permission of the rights holder.

Rights Holder: Asiatic Herpetological Research Society \& Chengdu Institute of Biology, Chinese Academy of Science

License: http://creativecommons.org/licenses/by-nc-sa/3.0/

Rights: https://biodiversitylibrary.org/permissions

This document was created from content at the Biodiversity Heritage Library, the world's largest open access digital library for biodiversity literature and archives. Visit BHL at https://www.biodiversitylibrary.org. 